\title{
Paste thickener benefits for soda ash: liquor recovery, mine backfill and surface stack
}

\author{
J Johnson WesTech Engineering Inc., USA \\ L Webb WesTech Engineering Inc., USA
}

\begin{abstract}
The benefit of paste and thickened tailings (P\&TT) was used for decades in the trona industry with a high-density type thickener installed as early as 1994. The extraction process produced supersaturated liquor, which makes liquor recovery paramount. The insoluble material consisting largely of clays and silts produces the common problem of safe containment of the tailings. Both mine backfill and surface stacking of the tailings are being used.

This paper provides a commodity review for trona, discussing the benefit of paste-type thickeners in the soda ash circuit. The topics include recovery from counter current decantation (CCD) circuits versus dilution washing; before and after retrofit data establishing improved underflow density and clarity from the latest thickener designs and operation; and the difficulties of surface stacking and drying due to residual soda ash forming a decahydrate crust sealing the stack and preventing drying.
\end{abstract}

The trona industry provides a good review of paste-type thickeners and their benefits.

Keywords: paste thickeners, counter current decantation, surface stacking, trona, retrofit modernisation

\section{$1 \quad$ Introduction}

Natural trona (sodium carbonate compound) reserves are found in the USA, Botswana, Mexico, Turkey, Uganda, Kenya and China. The USA has more than $90 \%$ of the known bedded trona reserves. Soda ash is also produced synthetically, primarily in China and India (Gregory 2014; Kostick 2013). The processing of trona to produce soda ash requires large volumes of water as the run-of-mine ore grade is over $80 \%$ value. The recovery process for soda ash produced from trona includes crushing and grinding, calcination, hot water dissolution, settlers to recover the pregnant liquor and reject the insoluble solids, purification and filtration, and finally evaporation crystallisation. The supersaturated liquor is first recovered in a primary thickener. The clarifier underflow weight percent is limited due to the rich liquor ( $\sim 1.3$ specific gravity, SG) and fine grain insoluble solids (40-50\% passing 37 microns) to about $15-20 \mathrm{wt} \%$ in high rate thickeners. The final stage (washed) tailings can be thickened in high rate thickeners to $26-32 \mathrm{wt} \%$ solids. The process water requirements for this type of circuit can be substantial. To dissolve one tonne of ore requires about 1.5-2 tonnes of water.

Non-Newtonian suspensions (referred to as paste and thickened tailings (P\&TT)) produced by paste-type thickeners have shown significant benefits. The benefits include improved water recovery, improved deposition stability and strength with solar drying, reduced rainwater erosion due to mild angle of repose, reduced operation cost, and improved rehabilitation (Brackebusch \& Shillabeer 1998; Fourie 2015). The unique design of paste-type thickeners includes steeper floor slopes, low-profile rake arms, rake blades mounted on posts, dewatering pickets, very heavy-duty drives, and tanks to promote deep beds with long solids retention time. These thickener features promote dewatering of the process stream to a weight per cent consistency where the suspensions have non-Newtonian properties. Non-Newtonian properties like relative non-settling, non-segregating, maintaining a shape, and high solids content provide the P\&TT benefits discussed. 
The soda ash pregnant slurry is thickened in insulated clarifiers to recover the pregnant liquor. The liquor is a density of $1.3 \mathrm{t} / \mathrm{m}^{3}$ and is filtered to remove impurities that will degrade the final products if not removed.

The traditional washing circuit used is a dilution/settling method where the underflow from the primary clarifier is diluted with weak liquor (recycled water), fresh water (make-up water) or a combination of the two and fed to a secondary thickener. This secondary thickener recovered liquor is reused in the plant and the underflow is then diluted again and thickened in a third thickener. The clarifier used produces underflow wt\% solids in the range of 16-32 wt\% for these two stages of washing, with the final wash tailings being sent to a conventional slurry pond. The water associated with the tailings still contains as much as $5-8 \mathrm{wt} \%$ soda ash. Water that is decanted from the ponds is sent to drying ponds where the water is evaporated and the soda ash crystallises as a decahydrate. Periodically, the decahydrate is mined and returned to the plant for recovery.

Some sites have incorporated the counter current decantation (CCD) washing method for the recovery of soda ash instead of the dilution/settling method for the two-stage washing circuit. This improves the washing efficiency of the circuit. With either washing method, the efficiency of each stage is a direct result of the underflow solids concentration. The greater the underflow wt\%, the less water (containing value) being sent to the next stage.

\section{Paste thickener application to soda ash process}

The ability of the paste-type thickeners to produce a non-Newtonian underflow P\&TT is dependent on the thickener design and operating conditions. In stating that, it is easy to assume that these designs and operating conditions are commonly known. Although the technology has been on the market for a couple of decades, successful implementation is not assured. This paper discusses three major benefits of paste-type thickeners in the soda ash market that also apply to other markets. These three benefits are:

1. Improved water recovery.

2. Surface stacking of tailings, reducing the risks and cost of containment.

3. Benefits of implementing the latest thickener designs and operation.

\subsection{Improved water recovery}

For a given thickener design and operating conditions, the underflow produced by a paste-type thickener will depend on the yield stress curve of the material being processed. The yield stress curve will be unique for each sample collected from the thickener. The yield stress (measured in Pa) versus wt\% solids relationship will change as the stream parameters vary. The normal process streams will vary relatively quickly. Parameters like particle size distribution (PSD), mineralogy and water chemistry will vary producing unique yield stress curves for each sample.

The yield stress curves for three trona samples are provided in Figure 1. These samples are from two different plants. The Plant A samples are from two different locations in the process. The primary sample is from the primary clarifier underflow with high liquor density ( 1.3 SG). The secondary/last stage Plant A sample is from the tailing stream sent to the tailings storage facility, which has been washed in the two-stage plant washing circuit resulting in a liquor density of $\sim 1.05 \mathrm{t} / \mathrm{m}^{3} \mathrm{SG}$. The Plant B sample also has the lower liquor SG but has a finer PSD. Therefore, if these slurries containing these solids were dewatered in a thickener designed and operated to produce a $60 \mathrm{~Pa}$ underflow, Plant A Primary would be $38 \mathrm{wt} \%$, Plant A last stage would be $55 \mathrm{wt} \%$ and Plant B final stage would be $43 \mathrm{wt} \%$. Feed parameters will affect the underflow produced from a paste-type thickener. 


\section{Trona Yield Stress Curves}

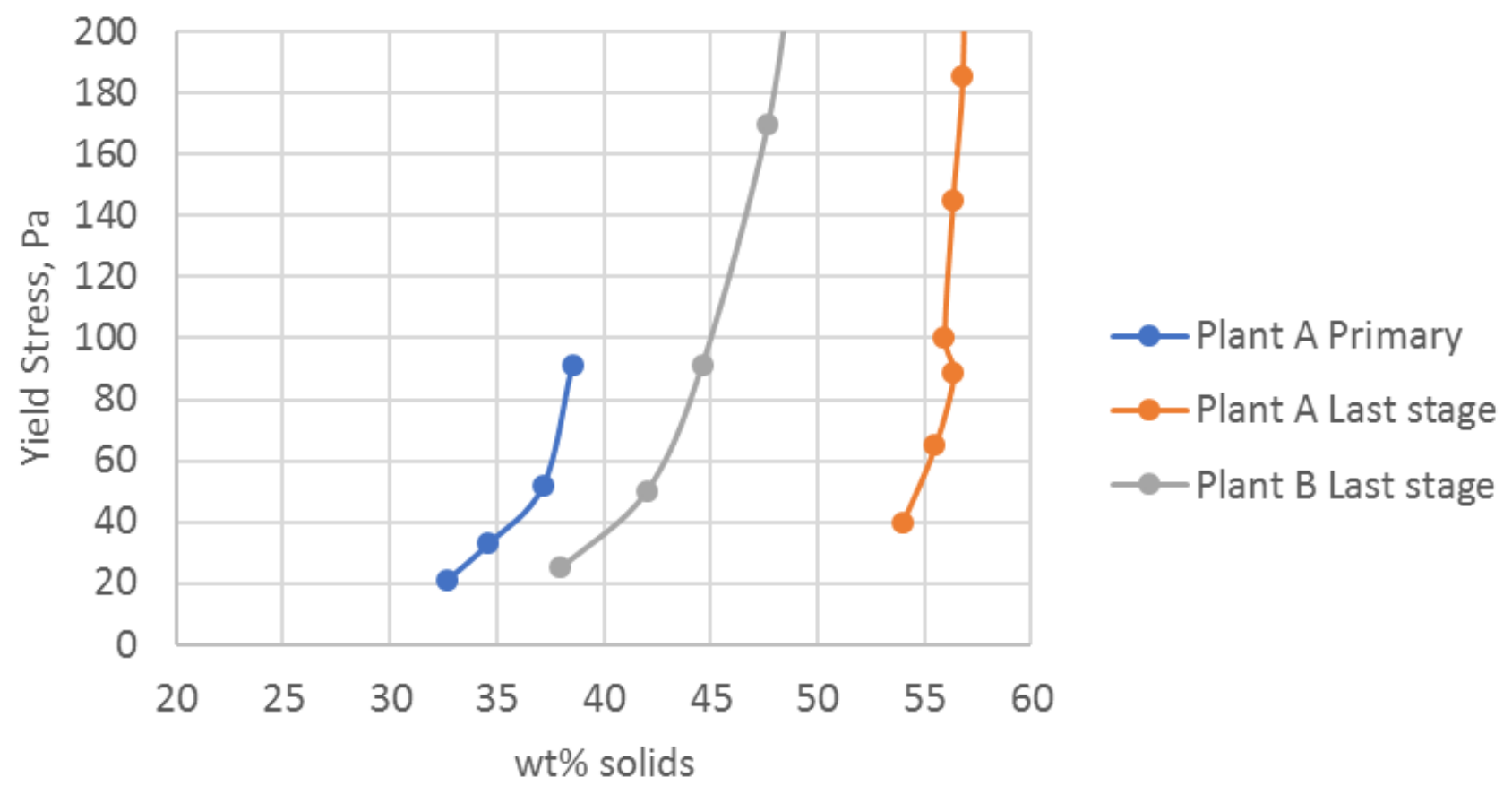

Figure 1 Example of yield stress for trona process streams

The underflow wt\% solids produced from high rate thickeners and paste-type thickeners for several plants are shown in Table 1. The plants use a combination of thickener types.

Table 1 Thickener underflow for primary and washing thickeners

\begin{tabular}{llll}
\hline & $\begin{array}{l}\text { Primary clarifier } \\
\text { (HRT) }\end{array}$ & $\begin{array}{l}\text { Secondary - first } \\
\text { wash stage (HRT) }\end{array}$ & $\begin{array}{l}\text { Tertiary - second } \\
\text { wash stage }\end{array}$ \\
\hline Plant A (thickener type*) & $16-20$ & $25-28$ & $28-30$ (HRT) \\
Plant B (thickener type) & $16-22$ & $21-23$ & $50-52$ (PT) \\
Plant C (thickener type) & $16-22$ & $30-35$ & $45-52$ (PT) \\
Plant D (thickener type) & $15-18$ & $18-20$ & $30-40$ (PT) \\
Plant F (thickener type) & $13-15$ & $20-22$ & \\
\hline
\end{tabular}

*HRT = high rate thickener; $\mathrm{PT}=$ paste-type thickener

These actual performance values show a dramatic increase in underflow wt\% between high rate thickeners and paste-type thickeners. Increasing the underflow from about 28 to over $50 \mathrm{wt} \%$ recovers about $70 \%$ of the liquor sent to tailings with the HRT. For the dilution/settling washing method, that translates to $70 \%$ reduction in soda ash losses to the pond and that recovery is at the plant.

This increase in underflow has an even more profound effect when the plant uses CCD methods, even for a two-stage system. The soda ash recovery process requires fixed volumes of water and is supplied from recycled weak liquor and fresh water. The dilution/settling method adds the dilution water to each stage instead of adding the water to the final stage first (like the CCD method) and then using the last stage overflow for the dilution of the feed to the previous stage. The calculation of a CCD circuit can be complex, even for a circuit with few stages. For simplicity, the calculation is not provided in this paper. However, when two stages of the dilution/settling method with high rate thickeners were used at one site, the first stage received $85 \%$ of the wash water volume and the second stage received the last $15 \%$. The amount of soda ash contained in the 
discharged tailings was about 8-10 tonne per hour, tph. If the same amount of water was used in a two-stage CCD method wash circuit (first stage is HRT and second stage is PT), the final tailings liquor would contain less than $0.5 \mathrm{tph}$. This dramatic decrease is a result of the CCD method and the improved efficiency when using paste-type thickeners. The dramatic increase in underflow density results in several benefits:

- Reduced soda ash losses to the pond by $70 \%$ for dilution/settling washing method.

- Improved underflow density combined with CCD washing method produces dramatic improvements in recovery (on the order of $90+\%$ reduction in lost soda ash).

- Reduced or eliminated need to reprocess the decahydrate that crystallises in the evaporation ponds, as liquor will be recovered at the plant. This reprocessing of the decahydrate includes maintenance of the drying pond, mining crystallised decahydrate, managing stockpile, reprocessing and recovery of the associated soda ash.

- Reduced make-up water.

- Disposal of insoluble solids - backfill.

P\&TT underflow from the paste thickeners is currently used to backfill the mine and to store tailings in surface stack aboveground. The most common method to mine the bedded trona reserves is room and pillar. The seams are 1.2-6 $\mathrm{m}$ thick. Barriers are prepared to contain the backfill material. High rate thickener underflow and P\&TT are both being used. Alternatively, the room roof is allowed to collapse, and the tailings are pumped into the same area. Any excess or free water must be managed. The water can generate an issue of ore dissolution in the mine. The resulting mine liquor is more difficult to process due to impurities not normally dissolved in the process plant. The higher underflow density of P\&TT greatly reduces the free water issue. The use of P\&TT targets a $250 \mathrm{~mm}$ slump from a $300 \mathrm{~mm}$ cone slump test. The backfill is generally delivered using piston pumps.

\subsection{Disposal of insoluble solids - surface stack}

The practice of surface stacking is becoming more prevalent. The advantage of recovering more water at the plant (keeping the soda ash in the process water instead of sending it to ponds to be recovered later as decahydrate) has significant cost savings.

P\&TT pilot plant studies identified operating parameters for successful surface stacking of insoluble solids. The ability to produce P\&TT material, which produces a 1-3\% angle of repose when deposited, was confirmed. Drying investigations conducted as part of the study showed a critical stream parameter needed for proper drying - the degree of washing and the final liquor density must be below $1.03 \mathrm{t} / \mathrm{m}^{3} \mathrm{SG}$. The decahydrate crystallising on the surface creates a barrier preventing the normal rapid drying of the P\&TT. Figure 2 shows a top view of the drying test trough with liquor SG of 1.08. The white decahydrate crystals can be seen covering the total surface. Table 2 shows the drying data for two tests: Test 1 contained $1.02 \mathrm{t} / \mathrm{m}^{3}$ liquor SG; and Test 2 contained $1.08 \mathrm{t} / \mathrm{m}^{3}$ liquor SG. The decahydrate crystals crust over the surface inhibited drying. Test 1 had large cracks over the whole trough after one week while Test 2 had not started to crack after one week. 


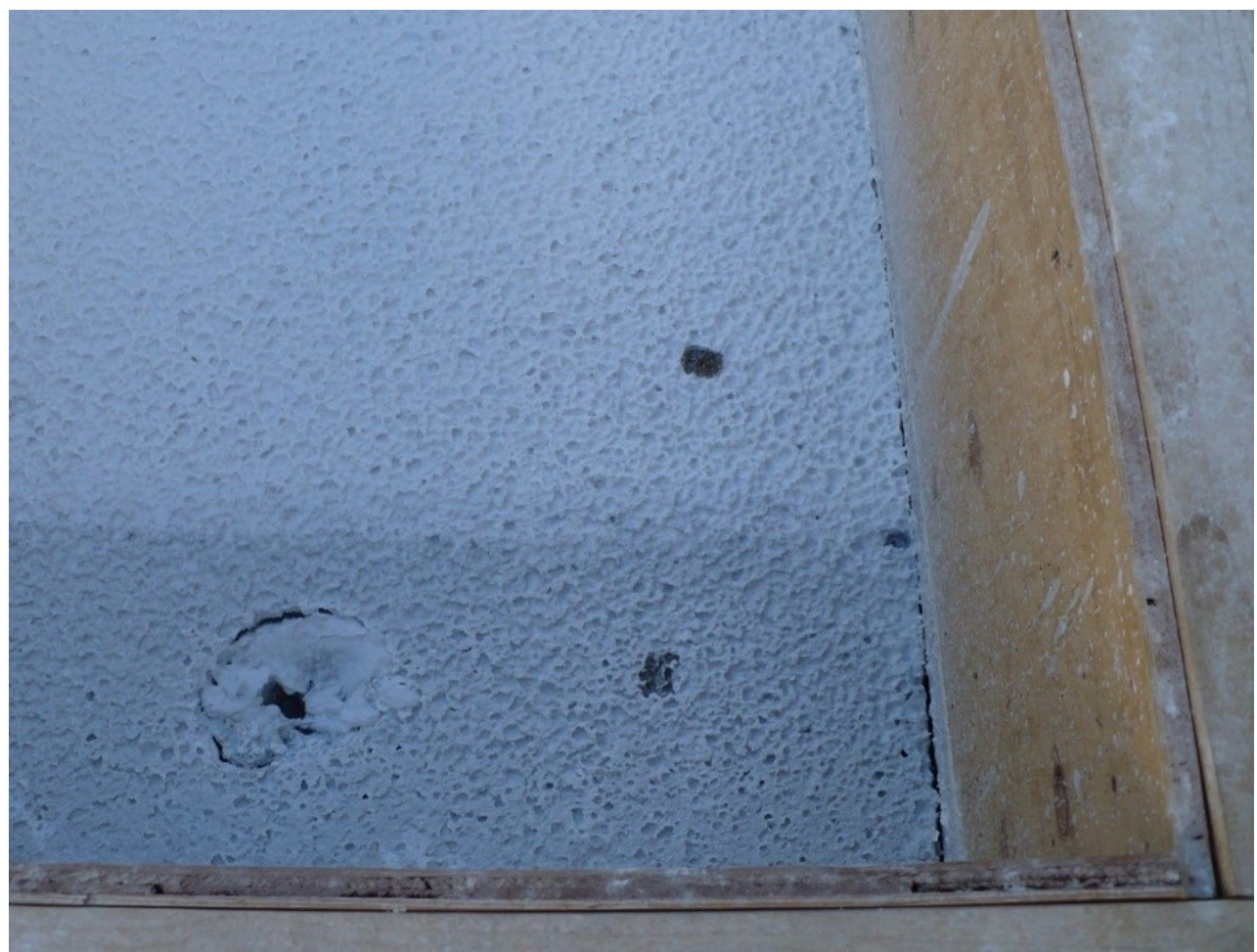

Figure 2 Dry trough with liquor SG at 1.8 (sample site lower left)

Table 2 Pilot plant drying tests - varying liquor SG

\begin{tabular}{llll}
\hline & Initial wt\% solids & Dry - 1 day & Dry - 1 week \\
\hline Test 1 (1.02 liquor SG) & 31.0 & 34.4 & 42.6 \\
Test 2 (1.08 liquor SG) & 30.0 & 31.5 & 35.3 \\
\hline
\end{tabular}

Figure 3 shows the surface stack in operation. The tailings enter the stack on the right of the photo and flow to the left. The foreground of the photo shows the dried layer. The decahydrate is present but at a concentration that does not prevent drying. This site uses the dry tailings for berm building.

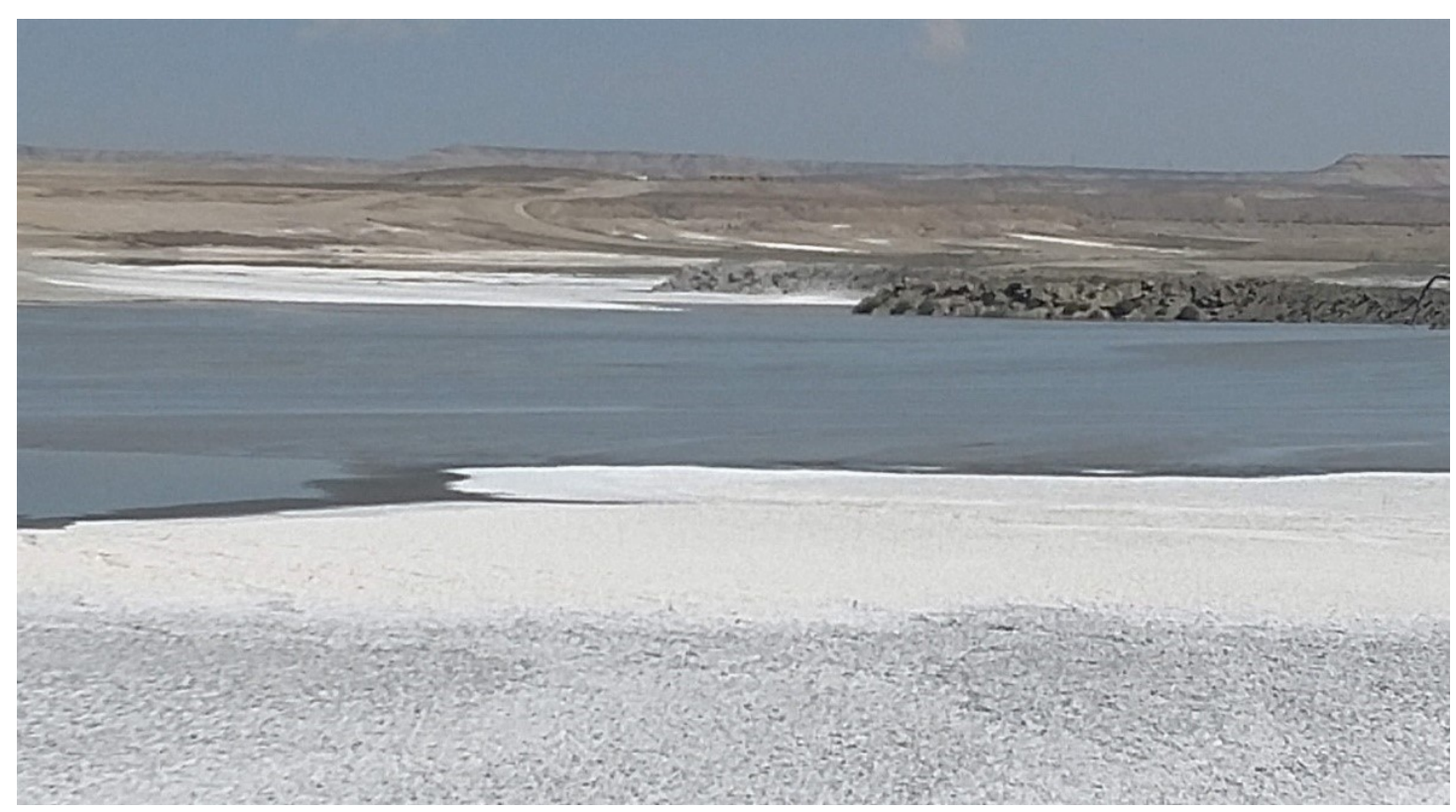

Figure 3 Surface stacking in progress 
The use of P\&TT for insoluble solids disposal has benefits such as:

- Feasible P\&TT surface stacking deposition of tailings.

- Insoluble tailings exhibiting P\&TT traits for wt\% solids range of 30-56, depending on the site, PSD and liquor SG.

- Drying of deposited stack requires residual liquor density to be below $1.03 \mathrm{t} / \mathrm{m}^{3}$ due to decahydrate crystal crust formation.

- Reduced problem of water in the mine when tailings are used for backfilling.

- Improved water processing as water dissolves ore and other impurities.

\section{Modernisation}

The trona industry was using paste-type thickeners for decades with a high-density thickener installed in 1994. This was near the beginning in the development of paste thickeners. The underflow from this thickener was used in both backfill and surface stacking of the insoluble solids tails. The P\&TT would be sent to the surface when the mine was not ready for the flow. The author, as part of PasteThick Associates, conducted an audit of the site's system. As paste-type thickener design had improved over the period of 1994 to 2006, it was recommended to modernise the thickener by retrofitting the latest designed mechanism. The retrofit mechanism had features such as low-profile rake arms, dewatering pickets, and blades spaced from the arms on posts. The before and after retrofit data is shown in Figure 4. The density of the underflow for seven months before and three months following the retrofit are provided. The after retrofit data shows both improved consistency and increased density.

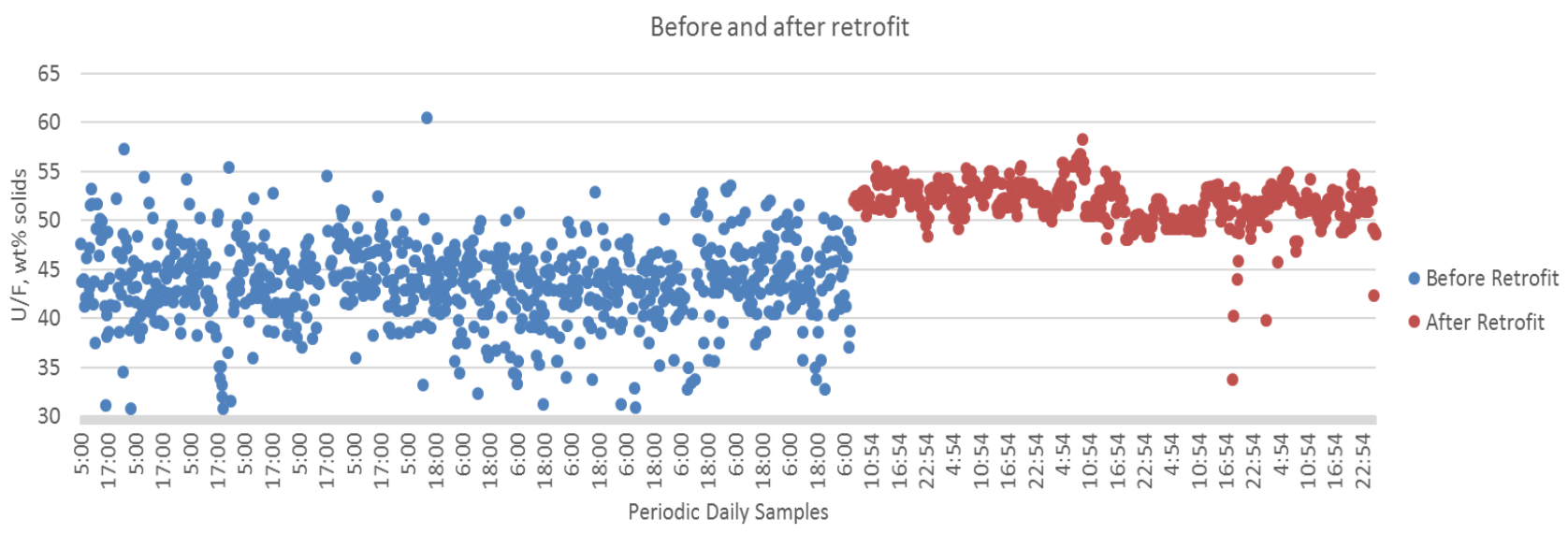

Figure 4 Before and after modernisation of paste-type thickener mechanism

Another recent improvement in the thickener has focused on the feedwell design. The benefits and description of the WesTech patented EvenFlo ${ }^{T M}$ feedwell were presented in Johnson and Accioly (2017). The design uses a two-stage feedwell that receives the feed flow in an inner raceway that directs the feed stream radially out into the feedwell. The results of this design eliminate short circuiting of flows and improves mixing. The overflow suspended solids are reduced as the solids have consistent residence time in the feedwell at optimum mixing to be flocculated and settled. Figure 5 shows a cross-section through the feedwell of a computational flow dynamics analysis. The resulting flows within the EvenFlo can be seen with mixing around the full circumference and even discharge into the thickener. The benefits of this feedwell design for the trona plant is improved clarity as the liquor contains the product and reduced flocculant dosage. 


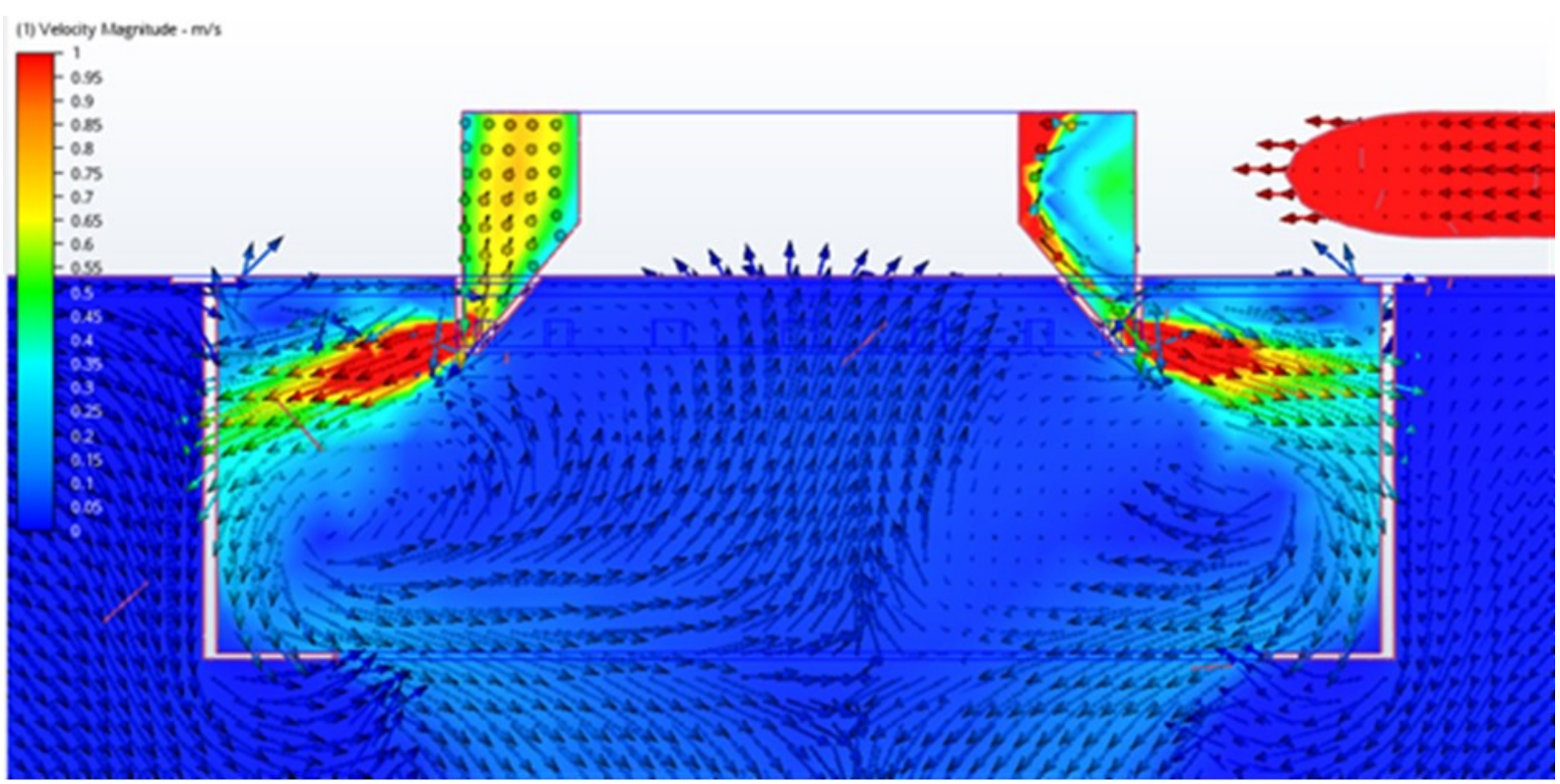

Figure 5 Cross-section of computational flow dynamics showing flow patterns in the WesTech EvenFlo

The primary conventional shelfed feedwell clarifier was replaced with the EvenFlo. The pre- and post-retrofit data is given in Table 3. The performance trend analysis shows that over a 22-week period (pre-retrofit = 11 weeks, post-retrofit $=11$ weeks) there was a dramatic improvement in overflow clarity ( $50 \%$ reduction), reduction in polymer dosage ( $34 \%$ reduction) and an increase in underflow density ( $16 \%$ increase). There was improved clarity with reduced polymer dosage. The improved efficiency of the EvenFlo produced the dramatic improvement in the overflow while reducing the flocculant consumption.

Table 3 Before and after EvenFlo retrofit in primary clarifier

\begin{tabular}{lllll}
\hline & $\begin{array}{l}\text { Plant feed } \\
\text { (tph) }\end{array}$ & $\begin{array}{l}\text { Overflow } \\
\text { clarity (tph) }\end{array}$ & $\begin{array}{l}\text { Floc }\left(\mathbf{m}^{3} / \mathrm{h}\right) \text { dosing rate } \\
\text { per insoluble solids (tph)] }\end{array}$ & $\begin{array}{l}\text { Underflow } \\
\text { (wt\%) }\end{array}$ \\
\hline Pre (11 weeks average) & 264 & 0.021 & 0.38 & 17.3 \\
Post (11 weeks average) & 254 & 0.010 & 0.25 & 20.0 \\
\hline
\end{tabular}

\section{Conclusion}

The ability of paste-type thickeners to produce significantly greater underflow density has several benefits, particularly for the trona industry. These benefits include:

- The trona process dissolves the ore producing a pregnant liquor and the improved water recovery is very valuable. This recovery of the soda ash at the plant reduces the need to manage a decahydrate recovery system to return lost soda ash in the free water of high rate thickener underflow.

- Washing of insoluble solids to recover the soda ash greatly improves with the higher density of paste-type thickeners. Dilution/settling and CCD circuits have dramatic increases in recovery due to the improved efficiency of a washing stage with the use of paste-type thickeners.

- P\&TT surface stacking of the tailings is feasible and, when the washing efficiency produces final liquor with a density less than $1.03 \mathrm{t} / \mathrm{m}^{3}$, proper rapid drying occurs providing the stable deposit.

- P\&TT is used as backfill and greatly reduces the free water sent to the mine, giving the benefit of less ore dissolution and mine water management issues. 


\section{References}

Brackebusch, F \& Shillabeer, J 1998, 'Use of paste for tailings disposal', in M Bloss (ed.), Proceedings of the Sixth International Symposium on Mining with Backfill, The Australian Institute of Mining and Metallurgy, Melbourne, pp. 53-58.

Fourie, AB 2015, 'Above ground disposal', in RJ Jewell \& AB Fourie (eds), Proceedings of the 18th International Seminar on Paste and Thickened Tailings, Australian Centre for Geomechanics, Perth, pp. 195-216.

Gregory, RW 2014, Wyoming Trona, Wyoming State Geological Survey, Laramie.

Johnson, JL \& Accioly, A 2017, 'Feedwell is the heart of a thickener', in AX Wu \& RJ Jewell (eds), Proceedings of the 20th International Seminar on Paste and Thickened Tailings, University of Science and Technology Beijing, Beijing, pp. 23-28.

Kostick, DS 2013, U.S. Geological Survey, Mineral Commodity Summaries, pp. 148-149. 